OPEN ACCESS

Edited by:

Vanessa Pinho,

Federal University of Minas

Gerais, Brazil

Reviewed by:

Luciana Padua Tavares,

Harvard Medical School, United States

Massimo Locati,

University of Milan, Italy

Janos G. Filep,

Université de Montréal, Canada

*Correspondence:

Derek M. McKay

dmckay@ucalgary.ca

'Present address:

Nicholas Jendzjowsky,

Respiratory Medicine \& Exercise

Physiology, The Lundquist Institute

for Biomedical Innovation at

Harbor-UCLA Medical Center,

Torrance, Los Angeles,

CA, United States

Specialty section:

This article was submitted to

Inflammation,

a section of the journal

Frontiers in Immunology

Received: 20 July 2021

Accepted: 15 September 2021

Published: 06 October 2021

Citation:

Callejas BE, Blyth $G A D$,

Jendzjowsky N, Wang $A$,

Babbar A, Koro K, Wilson RJA,

Kelly MM, Cobo ER and

McKay DM (2021) Interleukin-4

Programmed Macrophages

Suppress Colitis and Do Not

Enhance Infectious-Colitis,

Inflammation-Associated Colon Cancer or Airway Hypersensitivity.

Front. Immunol. 12:744738. doi: 10.3389/fimmu.2021.744738

\section{Interleukin-4 Programmed}

Macrophages Suppress Colitis and Do Not Enhance Infectious-Colitis, Inflammation-Associated Colon Cancer or Airway Hypersensitivity

\author{
Blanca E. Callejas ${ }^{1}$, Graham A. D. Blyth ${ }^{2}$, Nicholas Jendzjowsky ${ }^{3 \dagger}$, Arthur Wang ${ }^{1}$, \\ Anshu Babbar ${ }^{4}$, Konstantin Koro ${ }^{5}$, Richard J. A. Wilson ${ }^{3}$, Margaret M. Kelly ${ }^{5,6}$, \\ Eduardo R. Cobo ${ }^{4}$ and Derek M. McKay ${ }^{1 *}$
}

1 Gastrointestinal Research Group, Inflammation Research Network and Host-Parasite Interaction Group, Department of Physiology and Pharmacology, Calvin, Phoebe \& Joan Snyder Institute for Chronic Diseases, Cumming School of Medicine, University of Calgary, Calgary, AB, Canada, ${ }^{2}$ Department of Microbiology, Immunology and Infectious Disease, Cumming School of Medicine, University of Calgary and Production Animal Health, Faculty of Veterinary Medicine, University of Calgary, Calgary, AB, Canada, ${ }^{3}$ Department of Physiology and Pharmacology, Hotchkiss Brain Institute, Cumming School of Medicine, University of Calgary, Calgary, AB, Canada, ${ }^{4}$ Production Animal Health, Faculty of Veterinary Medicine, University of Calgary, Calgary, AB, Canada, ${ }^{5}$ Department of Pathology and Laboratory Medicine, Calvin, Phoebe \& Joan Snyder Institute for Chronic Diseases, Cumming School of Medicine, University of Calgary, Calgary, AB, Canada, ${ }^{6}$ Alberta Children's Hospital Research Institute, Cumming School of Medicine, University of Calgary, Calgary, AB, Canada

The murine interleukin-4 treated macrophage (MIL4) exerts anti-inflammatory and prohealing effects and has been shown to reduce the severity of chemical-induced colitis. Positing M(IL4) transfer as an anti-inflammatory therapy, the possibility of side-effects must be considered. Consequently, bone marrow-derived M(IL4)s were administered via intraperitoneal injection to mice concomitant with Citrobacter rodentium infection (infections colitis), azoxymethane/dextran sodium sulphate (AOM/DSS) treatment [a model of colorectal cancer (CRC)], or ovalbumin sensitization (airway inflammation). The impact of $M(I L 4)$ treatment on C. rodentium infectivity, colon histopathology, tumor number and size and tissue-specific inflammation was examined in these models. The anti-colitic effect of the M(IL4)s were confirmed in the di-nitrobenzene sulphonic acid model of colitis and the lumen-to-blood movement of $4 \mathrm{kDa}$ FITC-dextran and bacterial translocation to the spleen and liver was also improved by M(IL4) treatment. Analysis of the other models of disease, that represent comorbidities that can occur in human inflammatory bowel disease (IBD), revealed that $M(I L 4)$ treatment did not exaggerate the severity of any of the conditions. Rather, there was reduction in the size (but not number) of polyps in the colon of AOM/DSS-mice and reduced infectivity and inflammation in C. rodentium-infected mice in M(IL4)-treated mice. Thus, while any new 
therapy can have unforeseen side effects, our data confirm and extend the anti-colitic capacity of murine $\mathrm{M}(\mathrm{IL} 4)$ s and indicate that systemic delivery of one million M(IL4)s did not exaggerate disease in models of colonic or airways inflammation or colonic tumorigenesis.

Keywords: intestinal inflammation, macrophage-based therapy, colitis-associated colorectal cancer, Citrobacter rodentium, airway inflammation

\section{INTRODUCTION}

Typically associated with the phagocytosis of microbes, macrophages perform a myriad of functions in host defense and homeostasis. This versatile cell is highly responsive to its' microenvironment and has been broadly classified into (1): classically activated macrophages (CAMs) that are considered pro-inflammatory and are evoked by exposure to microbial stimuli and interferon- $\gamma$ (IFN $\gamma$ ); and (2), alternatively activated macrophages (AAM) elicited by, for example, cytokines, apoptotic bodies and immune complexes $(1,2)$. The AAM (or regulatory macrophage) exerts anti-inflammatory effects and promotes tissue repair and remodeling, angiogenesis, and wound-healing that involves interaction with fibroblasts $(3,4)$. Murine and human AAMs have the capacity to induce regulatory $\mathrm{T}$-cells $(5,6)$, suggesting important roles in regulating adaptive immunity and the creation of an immunoregulatory environment.

The demonstration of the murine AAM's ability to promote tissue repair, notably in the skin, but also the heart, kidney, and spinal cord, raises the possibility that these cells could be used for cellular immunotherapy (7-11). Prominent among AAMs is the IL-4 ( \pm IL-13) treated macrophage M(IL4). We showed that systemic delivery of in vitro differentiated murine M(IL4)s significantly reduced the severity of dinitrobenzene sulphonic acid (DNBS), oxazolone, and dextran sodium sulphate (DSS) induced colitis in mice: in contrast, the administration of CAMs differentiated in vitro with IFN $\gamma$ [or control $\mathrm{M}(0)$ ] did not impact the outcome of the colitic disease (12-14). This anti-colitic effect of murine M(IL4)s and other AAM phenotypes was subsequently supported by other studies (15-19). In accordance with these findings, it was recently shown that soluble mediators from human M(IL4)s stimulated epithelial (i.e. monolayers of the human colon-derived T84 cell line) wound repair in an in vitro assay and, that these cells inhibited DNBS-induced colitis in ragl ${ }^{-/}$mice (20).

Considerable proof-of-concept data for M(IL4)s as an anticolitic therapy are available; however, with any new therapy, there is the possibility of side-effects. For instance, would the M(IL4)s pro-healing effect, if uncontrolled, result in fibrosis? While not identical, the M(IL4) and other AAMs share some similarities with myeloid-derived suppressor cells (MDSC) and tumor-associated macrophages (TAMs), raising the possibility that M(IL4)s could promote or exaggerate tumorigenesis (21). It has also been suggested that in a TH2-type environment, AAMs could increase an individual's susceptibility to microbial infection (22).

Cognizant of these possibilities, the current study was designed to determine if murine M(IL4)s would affect the severity of disease in models of inflammation-associated colon cancer (CRC), infectious colitis and antigen-driven airways hypersensitivity. All of these conditions can be comorbidities in human inflammatory bowel disease (IBD), the target condition for M(IL4) treatment. The data herein, confirm and extend the anti-colitic effect of intraperitoneal delivery of M(IL4)s, and reveal that these cells, under the paradigms tested, did not boost tumor development in the azoxymethane $(\mathrm{AOM}) / \mathrm{DSS}$ model of CRC, or immune cell infiltration and lung histopathology in the ovalbumin model of airway hypersensitivity. Intriguingly, inflammation in Citrobacter rodentium-infected mice was reduced by M(IL4) co-treatment. These proof-of-principle findings lend support for M(IL4)s as an anti-colitic therapy, and if translatable to human, suggest that M(IL4) treatment side-effects may be limited and would not offset the therapeutic benefit of this cellular immunotherapy.

\section{MATERIALS AND METHODS}

Animal experiments were approved by the University of Calgary Animal Care Committee in compliance with the guidelines of the Canadian Council on Animal Care and administered under protocol AC17-0115.

\section{Differentiation of M(IL4)s}

Following a published protocol (13), bone marrow cells were isolated from femurs and tibias of $\mathrm{C} 57 \mathrm{BL} / 6 \mathrm{~J}$ or $\mathrm{BALB} / \mathrm{c}$ male mice (8-10 weeks old; Charles River Laboratories, Quebec, Canada). Cells were differentiated into macrophages by culture for 7 days in RPMI-1640 medium (Sigma-Aldrich) supplemented with $2 \%$ Pen/Strep, $1 \times$ GlutaMAX $^{\mathrm{TM}}, 20 \%$ fetal bovine serum (FBS) (all Gibco/Thermo Fisher Scientific) and 20 $\mathrm{ng} / \mathrm{mL}$ recombinant macrophage-colony stimulating factor $(\mathrm{M}$ CSF) (R\&D Systems Inc.), changing medium on day 2 and day 5. Macrophages were then polarized with murine recombinant IL-4 (20 ng/mL; 48h; Cedarlane Labs, Mississauga, Ontario, Canada). Conversion to an M(IL4) was tested by qPCR analysis of CD206, FIZZ1, Ym1, arginase-1 (Arg-1) and CD14 mRNA expression (See Supplementary Table 1 for PCR primer sequences) (13). We have previously shown that bone marrow-derived macrophages from $\mathrm{BALB} / \mathrm{c}$ and $\mathrm{C} 57 \mathrm{BL} / 6 \mathrm{~J}$ mice responded similarly to $20 \mathrm{ng} / \mathrm{mL}$ of IL-4 with up-regulation or arginase-1, FIZZ1 and Ym1 (12-14); only batches of M(IL4)s that showed this phenotypic response were used in the following studies.

Induction of DNBS-Colitis and Assessment Male BALB/c mice (8-10 weeks old) received an intraperitoneal (ip.) injection of $\mathrm{M}(\mathrm{IL} 4) \mathrm{s}\left(1 \times 10^{6}\right.$ in $\left.500 \mu \mathrm{L} \mathrm{PBS}\right)$, $48 \mathrm{~h}$ before 
intra-rectal instillation of DNBS (3 mg in $100 \mu \mathrm{L}$ 1:1 PBS/ethanol solution; MP Biomedicals, Santa Ana, CA) (12) [M(0) or M $(\mathrm{IFN} \gamma)$-treated cells were not used as a comparator cell type in these studies because, as noted, neither phenotype was anticolitic (12-14) and the present study was designed specifically to address the issue of putative side effects of administration of a therapeutic macrophage, i.e. M(IL4)]. Animals were monitored daily, weight recorded, and on humane euthanization, 72h after DNBS a macroscopic disease activity score was calculated on a 5point scale based on weight change, evidence of watery/bloody diarrhea, colon length and macroscopic ulceration. A portion of mid-colon was immersion fixed in $10 \%$ neutral-buffered formalin (NFB) for $72 \mathrm{~h}$, then paraffin-embedded, and sections $(5 \mu \mathrm{m})$ stained with hematoxylin and eosin (H\&E) and histopathology scored in a blinded fashion on a 12-point scale (12). Additional sections of the colon were de-waxed, rehydrated and then treated with anti-Ly6G antibodies (1:100, 16-9668-85; eBioscience) to identify neutrophil infiltration (see immunostaining protocol below) (23).

To assess epithelial barrier function, mice were gavaged with $100 \mu \mathrm{L}$ of $50 \mathrm{mg} / \mathrm{mL}$ FITC-dextran solution (FITC-4-kDa dextran; Sigma-Aldrich) $3 \mathrm{~h}$ before being euthanized. Serum was collected prior to necropsy, fluorescence intensity measured (excitation, $492 \mathrm{~nm}$; emission, $525 \mathrm{~nm}$ ), and FITCdextran concentrations read off a standard curve (24). Additionally, the spleen and liver were excised under sterile conditions, weighed, and homogenized in $3 \mathrm{~mL}$ of sterile PBS. Ten and $100 \mu \mathrm{L}$ of the homogenate were inoculated onto Luria broth (LB) agar plates and incubated at $37^{\circ} \mathrm{C}$ for $48 \mathrm{~h}$ in aerobic conditions. Subsequently, colony forming units (CFUs) were counted, corrected for sample dilution and are expressed as CFU/100 mg tissue (24).

As an indicator of local inflammation, segments of the colon were weighed, homogenized, and suspended in either hexadecyltrimethylammonium bromide (HTAB) buffer $(50 \mathrm{mg}$ tissue wet-weight $/ \mathrm{mL}$ ) for myeloperoxidase (MPO) activity or in sterile-PBS for measurement of cytokines. After homogenization, supernatants were collected and MPO activity was determined as before and represented as units $\mathrm{U}$ in $100 \mathrm{mg}$ of tissue, where $1 \mathrm{U}$ equals the amount of MPO required to degrade $1 \mu \mathrm{M} \mathrm{H}_{2} \mathrm{O}_{2} / \mathrm{min}$ at room temperature (12). Tissues homogenized in sterile-PBS were assessed for levels of IL- $1 \beta$, TNF- $\alpha$, IL-10 and CXCL1 by ELISA following the manufactures instructions (PeproTech, CranBury, NJ) (25).

\section{Citrobacter rodentium Infection and Assessment}

C57BL/6J mice (8-10 weeks old, originally purchased from The Jackson Laboratory housed for several generations in a pathogen-free environment at the Univ. Calgary) were injected with M(IL4)s $\left(1 \times 10^{6}\right.$ in $500 \mu \mathrm{L}$ PBS, ip.). Two days later, mice were orally gavaged with $C$. rodentium (strain DBS $100 ; 5 \times 10^{8}$ CFU in $200 \mu \mathrm{L}$ PBS $)(26,27)$. Feces were collected at 3-, 5-, and 7 -days post-infection (dpi), homogenized at $0.1 \mathrm{~g} / 1 \mathrm{~mL}$ of sterile PBS, then serial dilutions were added to MacConkey agar plates. After $24 \mathrm{~h}$ of aerobic culture at $37^{\circ} \mathrm{C}$, colonies were counted to obtain bacterial CFU/g (26). Mice were euthanized at $7 \mathrm{dpi}$, colon length measured, and segments of mid-colon processed for $\mathrm{H} \& \mathrm{E}$ staining. Fecal lipocalin-2 was measured as a general marker of inflammation by ELISA (R\&D Systems) and following the provided manufactures instructions $(26,27)$.

Total RNA was isolated from colon tissues (Aurum Total RNA Mini Kit, Bio-Rad Laboratories, Hercules, CA), quantified (Nanodrop 1000 Spectrophotometer, Thermo Fisher Scientific, Wilmington, DE), and $0.5 \mu \mathrm{g}$ of RNA converted to cDNA using iScript kit (Bio-Rad Lab, Canada). Quantitative real-time polymerase chain reaction (qPCR) was performed with SYBR Green Supermix (Bio-Rad, Cat. \# 1725274), which consisted of 40 amplification cycles per run (26) using primer sequences shown in Supplementary Table $\mathbf{1}$ and normalized to the housekeeping gene $18 \mathrm{~S}$ rRNA. Then the relative quantitative target gene expression of treatment groups was calculated by using $2^{-\Delta \Delta \mathrm{Ct}}$ method using control group as calibrator samples. Reactions were run in triplicate (the same process was applied to assess mRNA in bone marrow-derived macrophages).

To assess cellular composition of the colon, the distal $50 \%$ of the colon was opened longitudinally and incubated thrice for 15 min each in Hanks' Balanced Salt Solution (HBSS) with 10\% FBS and $2 \mathrm{mM}$ EDTA at $37^{\circ} \mathrm{C}$ to remove epithelial cells. After each incubation step, tubes were shaken for 10 seconds and medium containing epithelial cells was discarded. The lamina propria cells were centrifuged at $400 \mathrm{xg}$ for $10 \mathrm{~min}$ at $4^{\circ} \mathrm{C}$, and the pellet re-suspended in PBS (26). The cells were stained with antibodies against CD45 (563891; BD Biosciences), CD3e (557984; BD Biosciences), CD4 (561104; BD Biosciences), Ly6G (561104; BD Biosciences) and CD17a (506915; BioLegend) for $30 \mathrm{~min}$ at $4^{\circ} \mathrm{C}$ at the concentrations shown in Supplementary Table 2 . The cells were washed twice with PBS/ BSA/2mM EDTA and analyzed on a FACS CANTO-II (BD BioSciences).

\section{Colorectal Cancer Induction and Assessment}

Azoxymethane (AOM: Sigma, MO) + dextran sulphate sodium (DSS; MW 40,000, Alfa Aesar, Tewksbury, MA) is a common model of CRC $(23,28)$. Male C57BL/6J mice (8-10 weeks old) received $\mathrm{AOM}(12.5 \mathrm{mg} / \mathrm{Kg}$, ip.) and five days later, $2 \%$ DSS in drinking water for 7 days ad libitum followed by 14 days of regular water. This 7-day DSS-water +14 -day regular water regimen was repeated for two more cycles and mice were euthanized on day 113. One group of mice received M(IL4)s $\left(1 \times 10^{6}\right.$, ip. in $500 \mu \mathrm{L}$ PBS) 33 days after AOM (i.e. early) or 54 days after AOM injection. Upon euthanization, the colon was removed and opened longitudinally, polyps counted and measured, and tissues collected for H\&E staining (assessed in a blinded fashion by K. Koro), immunodetection of vimentin and E-cadherin, qPCR and for tissue levels of cytokines by ELISA.

Paraffin-embedded sections ( $5 \mu \mathrm{m}$ ) of the colon were de-waxed, rehydrated and then treated with anti-vimentin (1:100, 3932S; Cell Signaling) or anti-E-cadherin (1:300, 610181; BD eBioscience) antibodies overnight at $4^{\circ} \mathrm{C}$. Following washing, matched secondary antibodies were applied. For immunohistochemistry, 
the goat anti-rat-HRP conjugated was incubated for $30 \mathrm{~min}$ at room temperature (RT) (1;500, 405405, Biolegend). To visualize positive staining cells, tissue sections were stained with diaminobenzidine (DAB) (ab64238; Abcam) and counterstained with hematoxylin. For immunofluorescence goat anti-mouse Alexa fluor 488 (1:500, A11029; Invitrogen) and goat anti-rabbit Alexa fluor 594 (1:1000, A11005; Invitrogen) were incubated for $2 \mathrm{~h}$ at RT and after incubation, the nuclei were stained with DAPI at 1:1000 for $5 \mathrm{~min}$ (23). Representative images were captured on an Olympus BX41 microscope fitted with a U-TMAD $\mathrm{T}$ mount adapter, using cell Sens software (Olympus).

\section{Ovalbumin Sensitization and Airway Assessment}

Male BALB/c mice (8-10 weeks old) were immunized with ovalbumin $50 \mu \mathrm{g}$ (A5503; Sigma) and $1.5 \mathrm{mg}$ aluminum hydroxide (AC219130250; Fisher) dissolved in $100 \mu \mathrm{L}$ PBS (ip.) on days 1, 2 and 3. On days 15-18 (inclusive) mice were exposed to $20 \mathrm{~min}$ of 5\% nebulized OVA dissolved in PBS in an airtight chamber (29). Mice received $1 \times 10^{6} \mathrm{M}$ (IL4) (ip.) 2 days prior to the first dose of aerosolized OVA, and airway inflammation was assessed on day 19.

Bronchoalveolar lavage fluid (BALF) was collected from all mice. With the upper trachea cannulated, lungs were lavaged (1 mL per lavage $\mathrm{x} \mathrm{3}$ ) with $0.9 \% \mathrm{NaCl}$. Cells in the bronchoalveolar fluid were sedimented by centrifugation (20 min at $4500 x g, 4^{\circ} \mathrm{C}$ ) and re-suspended in PBS. A $100 \mu \mathrm{L}$ sample of BALF was centrifuged (Shandon Cytospin 4 cytocentrifuge, Thermo Scientific, Waltham, MA, $6 \mathrm{~min}$ at $4500 \mathrm{xg}$ ) and cells collected on non-coated glass slides, fixed in 95\% ethanol and H\&E stained. Total leukocytes were determined by hemacytometer counting and identification of 200 cells was completed according to standard morphologic criteria (30).

To assess lung pathology, the left lung was inflated with $10 \%$ $\mathrm{NBF}$ and fixed for $72 \mathrm{~h}$, processed to paraffin and $5 \mu \mathrm{m}$ sections were collected on coded slides, stained with $H \& E$ and scored in a blinded fashion (M. Kelly) using a published scale (31). The right lung was used to evaluate collagen levels by analysis of hydroxyproline using a commercial assay according to the manufacturer's instructions (K218, BioVision). Briefly, lungs were dried, weighed, and homogenized in $100 \mu \mathrm{L} \mathrm{ddH}_{2} \mathrm{O}$ for every $10 \mathrm{mg}$ of tissue; $100 \mu \mathrm{L}$ of concentrated $6 \mathrm{~N} \mathrm{HCl}$ were added to homogenized sample. Hydrolyzed samples were incubated at $120^{\circ} \mathrm{C}$ for 3 hours and then $30 \mu \mathrm{L}$ of each hydrolyzed sample transferred to a 96-well plate and $100 \mu \mathrm{L}$ of the Chloramine $\mathrm{T}$ reagent added to each sample and standard and incubated at room temperature for $10 \mathrm{~min}$. Finally, $100 \mu \mathrm{L}$ of the $\mathrm{DMAB}$ reagent was added to each well and incubated for $90 \mathrm{~min}$ at $60^{\circ} \mathrm{C}$. The amount of collagen generated was determined from a collagen calibration curve. The absorbance measured at $560 \mathrm{~nm}$ of each hydrolyzed sample (13).

\section{Statistical Analysis}

Data are presented as the mean \pm standard error of the mean (SEM). Data were analyzed and graphed using GraphPad Prism 6 (GraphPad Software). Unless otherwise stated, data were analyzed using a one-way analysis of variance (ANOVA) and when $\mathrm{p}<0.05$, pairwise comparisons of the means were examined with Tukey's test for parametric data. The Kruskal-Wallis test followed by Dunn's multiple comparison test was applied to nonparametric data.

\section{RESULTS}

\section{M(IL4) Transfer Protects Against Experimental Colitis}

To test the anti-colitic effect of M(IL4) transfer, macrophages from $\mathrm{BALB} / \mathrm{c}$ mice were differentiated in vitro with IL-4 and injected (ip.) into mice two days before induction of colitis with DNBS (Figure 1A). qPCR-analysis revealed increased CD206, FIZZ1, Ym1, arginase-1, and decreased CD14 mRNA expression confirming the identity of the murine M(IL4) (14) (Figure 1B). Mice treated with DNBS displayed a drop in body weight, a shorter colon, increased macroscopic disease scores (based on ulceration, lack of consistency in feces, and bleeding) and significant histopathology (Figures 1C-E). Consistent with previous findings in this model (13), mice treated with M(IL4)s had significantly less severe DNBS-induced colitis (Figures 1C-E), a range of benefit consistent with prior investigations (12-14), and these observations are supported by significantly reduced infiltration of $\mathrm{Ly}_{6 \mathrm{G}}{ }^{+}$cells and colonic MPO levels in tissues from M(IL4)+DNBS treated mice compared to tissue from DNBS-only treated mice (Figures 1F, G). qPCR analysis revealed increased expression of arginase-1, FIZZ1 and Ym1 in colon extracts from mice administered M(IL4)s (Figure 1H). While these data suggest localization of the transferred M(IL4)s to the colon, and are consistent with our prior immunodetection studies (14), they do not negate the possibilities that host resident macrophages up-regulated the expression of these genes or that other cells in the colon are responsible for, or contribute to, the increased arginase-1, FIZZ1 and Ym1.

To characterize the protective effects of M(IL4) on the epithelial layer in DNBS-treated mice, gut permeability was evaluated by orally administering FITC-dextran to mice. Measurement of FITC-dextran in the serum of DNBS-treated mice revealed a decrease in epithelial barrier function, that was not observed in DNBS+M(IL4)-treated animals (Figure 1I). Furthermore, the increased translocation of gut bacteria to the spleen and liver that occurred in DNBS-treated mice was significantly reduced in mice co-treated with M(IL4)+DNBS (Figure 1J). Collectively, these results confirm the protective role of M(IL4) in the DNBS-model of acute colitis.

\section{M(IL4) Reduces C. rodentium- Induced Colitis}

It has been suggested that M(IL4)s might predispose to bacterial infection (22). To assess this, and for comparison with chemicalinduced colitis, the effect of M(IL4) transfer (C57/BL6 mice) in the $C$. rodentium model of infectious colitis was examined (27) (Figure 2A). As an index of infection, fecal shedding of $C$. 
A

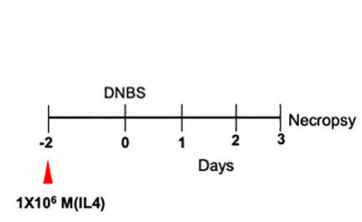

B

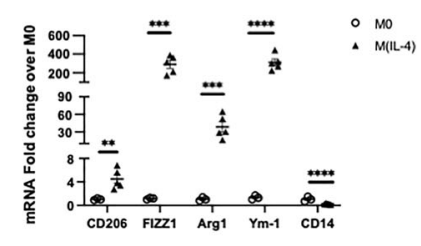

c

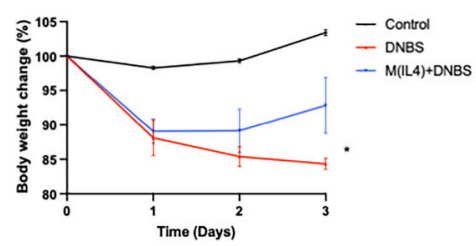

D

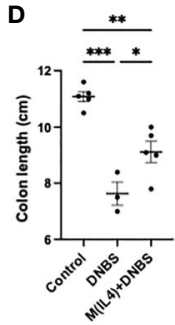

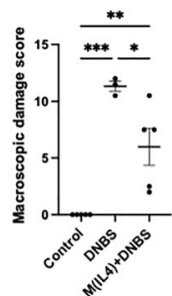

E

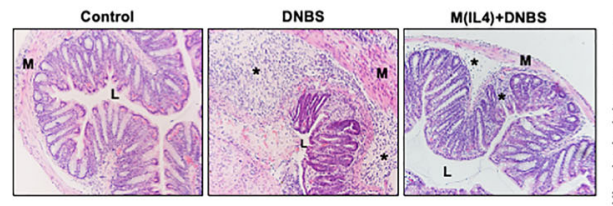

F

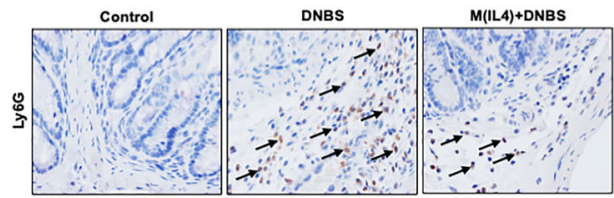

G

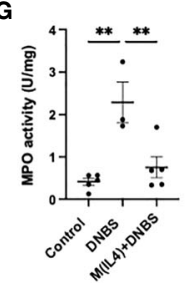

H
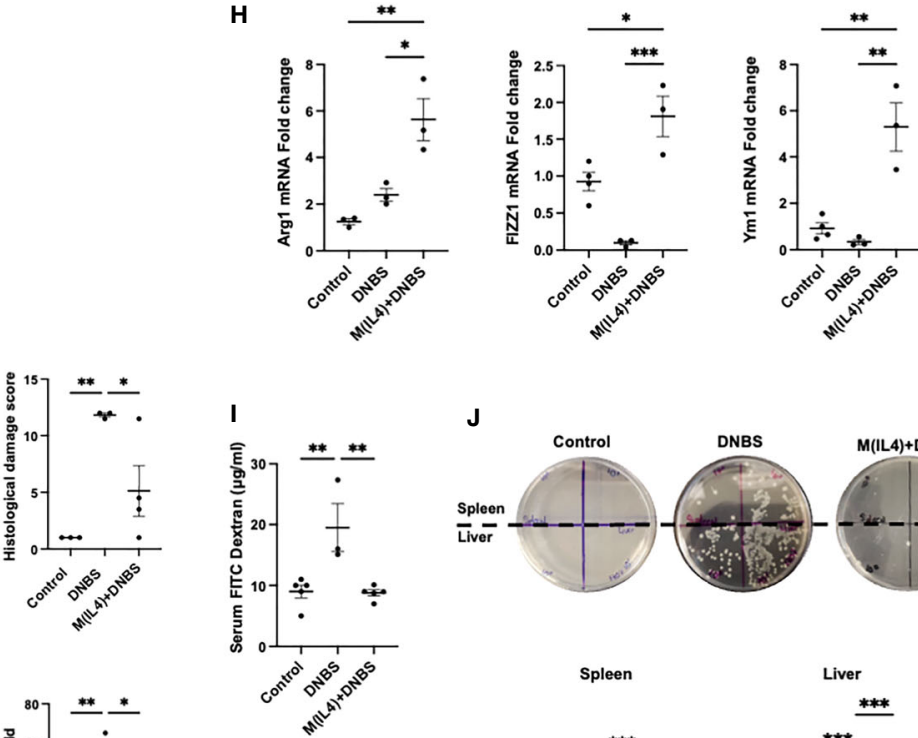

J
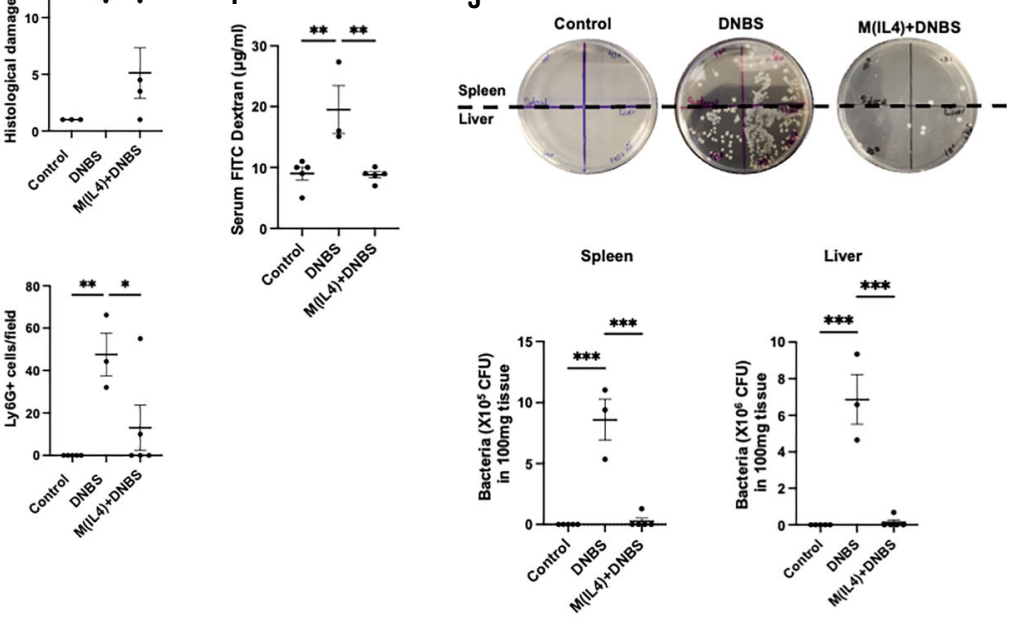

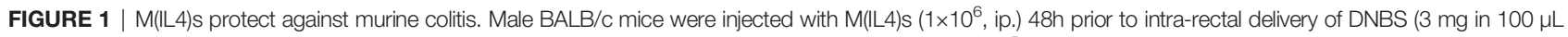
$50 \%$ ethanol) (A). Murine bone marrow-derived macrophages were treated with IL-4 (20 ng/mL per $2.5 \times 10^{5}$ cells/mL) for $48 \mathrm{~h}$ and conversion to an M(IL4) tested by expression of CD206, FIZZ1, Arg-1, Ym-1 and CD14 mRNA (B). During induction of colitis, weight was recorded daily (C). On necropsy at 72h post-DNBS, colon length was recorded, and a macroscopic disease activity score calculated (D). Panel (E) shows representative H\&E images (original magnitude, x20) and histopathology scores. Panel (F) shows representative images of Ly6G staining (original magnitude, $x 40$ ) and enumeration of Ly6G ${ }^{+}$cells/high power field of view $(n=3-4$ mice).

Myeloperoxidase (MPO) activity in colonic extracts as a measure of predominantly neutrophil infiltration is shown in panel (G). Panel (H) depicts qPCR data of arginase -1 (Arg1), FIZZ1 and Ym1 in colon extracts. Epithelial barrier function, as assessed by lumen-to-blood movement of 4kDa FITC-dextran and bacterial translocation to the spleen and liver is shown in panels (I, J) (data are means \pm SEM; $n=5$ mice; one-way ANOVA followed by Tukey's test for parametric data and Dunn multiple comparison test for nonparametric data; ${ }^{\star} \mathrm{p}<0.05,{ }^{\star *} \mathrm{p}<0.01,{ }^{\star \star \star} \mathrm{p}<0.001,{ }^{\star \star \star \star} \mathrm{p} \leq 0.0001$; M, outer layers of muscle; $\mathrm{L}$, gut lumen; ${ }^{*}$ inflammatory infiltrate).

rodentium was lesser in $\mathrm{M}(\mathrm{IL} 4)$-treated mice compared with untreated mice at 3, 5 and 7 days dpi ( $\sim 100$-fold reduction) (Figure 2B). While the shortening of the colon was not affected by M(IL4)-treatment (Figure 2C), this treatment did result in a mild, but statistically significant reduction in colonic histopathological damage and reduced neutrophils $\left(\mathrm{Ly}_{6 \mathrm{G}}{ }^{+}\right.$) and Th17 cell infiltrations in the colon (Figures 2D, E). The M(IL4)-treatment also reduced fecal levels of lipocalin-2 (Figure 2F) and colonic expression of IL-22, IL-17, IFN- $\gamma$ and Reg3g mRNA (Figure 2G) in C. rodentium-challenged mice. Overall, these findings indicate that M(IL4) transfer protects against colitis induced by $C$. rodentium-infection. 


\section{M(IL4) Transfer Does Not Influence the Progression of Colorectal Cancer}

Since macrophages activated by TH2-type cytokines share some characteristics of tumor-associated macrophages (TAMs) (32) we evaluated the putative tumorigenic property of M(IL4) transfer in a model of colitis-associated CRC. Two experimental paradigms were assessed: mice received M(IL4)s from C57/BL6 mice 33 days after the azoxymethane (AOM) or later in the progression of the CRC at 54 days after AOM treatment, and mice were humanely euthanized at day 113 (Figure 3A).

Systemic delivery of M(IL4)s at an early (day 33) or later (day 54) time-point in the progression of AOM/DSS-evoked CRC did not affect the number of macroscopically observable tumors, but did significantly reduce the number of tumors of $>2 \mathrm{~mm}$ diameter by $\sim 50 \%$ (Figures 3B, C). Blinded histological examination of colon demonstrated features of inflammation and neoplastic transformation (i.e. adenomas and adenocarcinoma). Background colonic mucosa inflammation was characterized by ulceration, neutrophilic cryptitis, hyperplastic/regenerative mucosa changes, and mixed lymphoplasmacytic inflammatory infiltrate. Neoplastic lesions showed altered cytology, including mucin depletion, nuclear stratification, increased nuclear/cytoplasmic ratio, and nuclear hyperchromasia. However, there were no significant microscopically identifiable differences between the degree of inflammation or types and configuration of adenomas between AOM/DSS-treated mice $\pm \mathrm{M}(\mathrm{IL} 4)$ at day 33 or day 54 groups (Figure 3D). In initial studies, $\mathrm{M}(0)$ s were used as a control group but the course of the CRC was not affected (total number of tumors; $\mathrm{AOM} / \mathrm{DSS}=13 \pm 1$ versus $\mathrm{AOM} / \mathrm{DSS}+\mathrm{M}(0) \mathrm{d} 33=13 \pm 2$ and $\mathrm{AOM} / \mathrm{DSS}+\mathrm{M}(0) \mathrm{d} 54=12 \pm 3$ : number of tumors $>2 \mathrm{~mm}$ diameter, AOM/DSS = $9 \pm 1, \mathrm{AOM} / \mathrm{DSS}+\mathrm{M}(0) \mathrm{d} 33=11 \pm 1$, $\mathrm{AOM} / \mathrm{DSS}+\mathrm{M}(0) \mathrm{d} 54=11 \pm 1$, mean \pm SEM, $\mathrm{n}=3-4)$.

Analysis of TNF- $\alpha$, CXCL1, IL-1 $\beta$, IL-10 protein and TGF- $\beta$ mRNA levels in colonic tissue segments devoid of obvious adenomas revealed the expected increases in these cytokines in the AOM/DSS mice were not affected by M(IL4) treatment (Figure 3E). On necropsy, qPCR of colonic extracts revealed increased mRNA for arginase-1, FIZZ1 and Ym1 in mice treated with $\mathrm{AOM} / \mathrm{DSS} \pm \mathrm{M}$ (IL4); however, while different from controls, expression in tissue from mice receiving M(IL4)s was not different from that from the AOM/DSS only group (Figure 3E). Similarly, immunodetection of the distribution of vimentin and E-cadherin, as markers of epithelial-mesenchymal transition (EMT), revealed no clear differences between tissue sections from AOM/DSS $\pm \mathrm{M}$ (IL4)-treated mice (Figure 3F). These data indicate that the transfer of M(IL4) in the early or later stages in this chemical model of CRC does not promote tumor progression.

\section{M(IL4) Transfer Does Not Exacerbate Airway Inflammation}

M2-macrophages have been presented as a concern in allergic asthma (33). In order to determine if M(IL4) transfer aggravates airways hypersensitivity, the OVA-sensitization model was employed. M(IL4)s from BALB/c mice were injected ip. 2-days before OVA challenge treatment (Figure 4A). In this classical model, OVA challenge of the sensitized mouse results in histopathology, remodeling of the lungs, and a substantial polymorphonuclear infiltration (mostly eosinophils but also some neutrophils): co-treatment with $\mathrm{M}$ (IL4)s had no appreciable effect on these aspects of the lung (Figures 4B, C). Analysis of lung collagen content revealed no significant increase in the OVA-challenged sensitized mice over controls and this was not affected by an M(IL4) treatment (Figure 4D). Thus, we have no evidence of M(IL4) aggravation of airway inflammation induced by OVA in sensitized and challenged mice.

\section{DISCUSSION}

The burden of IBD is increasing worldwide and despite the availability of new therapeutics, many patients receive minimal or no relief from these, and others become refractory to an effective treatment over time. Cellular therapy is an approach to auto-inflammatory disease in which, typically, mesenchymal stem cells or regulatory immune cells are used to blunt inflammation $(34,35)$. Expanding on the ability of macrophages to promote wound healing (3), we showed that murine M(IL4)s reduced disease in three models of chemicalinduced colitis (12-14); a finding confirmed by others using M(IL4)s or other phenotypes of regulatory macrophage (15-19). All medications have side effects, and this provided the impetus to determine if the anti-colitic M(IL4) would exacerbate other conditions that can occur in IBD.

M(IL4)s in infectious colitis, inflammation-associated CRC and airways inflammation was assessed for two main reasons. First, macrophages are important in combating microbes, are linked to cancer progression (i.e. TAMs), and a type-2 macrophage can be pro-fibrotic in the lung (36). Second, some patients with IBD have airway inflammation, increased incidence of CRC, and altered susceptibility to infection such as the increased presence of pathobiont $E$. coli associated with Crohn's disease (37-39). Systemic delivery of M(IL4)s via intraperitoneal injection did not aggravate the outcome in any of the models of disease, adding support for macrophages as a therapeutic target in $\operatorname{IBD}(20,40)$.

Within the context of helminth-therapy for colitis, we noted increased expression of colonic FIZZ1 and arginase-1 mRNA, markers indicative of an M(IL4) (12); however, these markers are not exclusive to M(IL4)s. To negate any ambiguity, bone marrow-derived macrophages treated with IL-4 were shown to block colitis (13). Complementing this finding, the current study shows that M(IL4)-treated mice following challenge with DNBS had lesser accumulation of neutrophils in the colon and increased enteric barrier function compared to DNBS-only treated mice.

C. rodentium is a natural Gram-negative attaching/effacing pathogen in mice, with pathogenesis in the colon similar to enteropathogenic Escherichia coli (EPEC) in humans (27). Postulating that M(IL4)s might counter classically activated macrophages' anti-microbial responses, mice were injected 
A

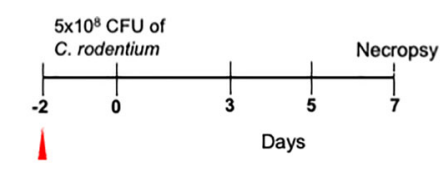

1X106 M(IL4)

B

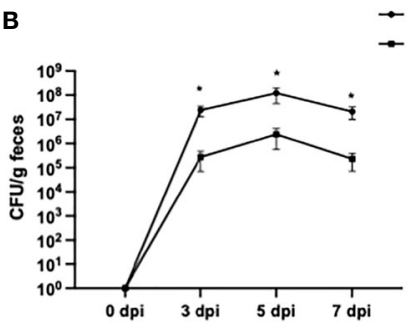

C

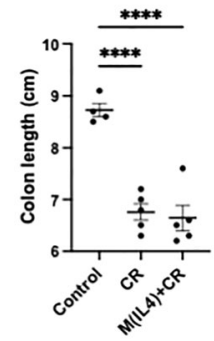

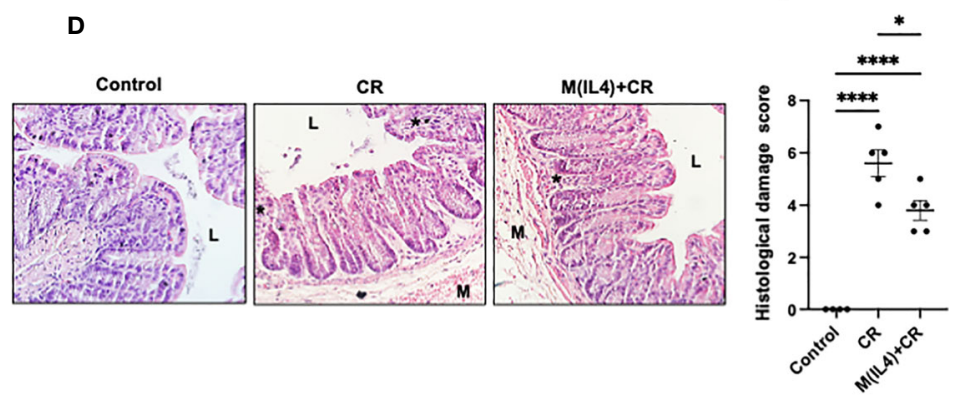

E

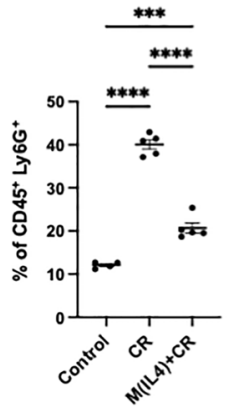

- CR

$M(I L 4)+C R$

$\mathbf{F}$
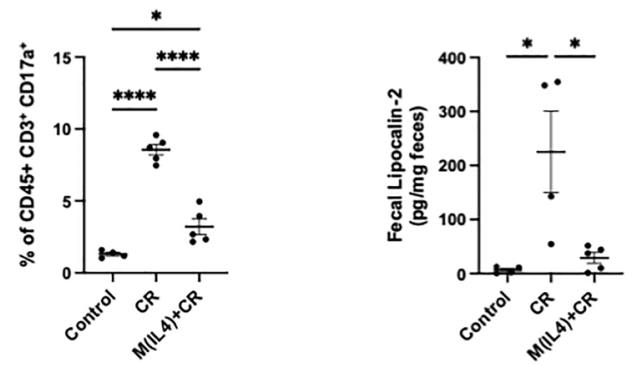

G
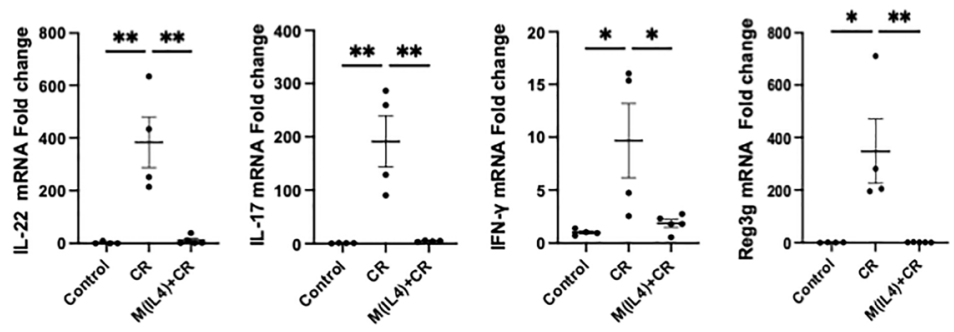

FIGURE 2 | M(IL4)s reduce colonic inflammation in mice infected with C rodentium. Male C57BL/6J mice were injected with M(IL4)s (1×106, ip.) and 48h later received $5 \times 10^{8} \mathrm{CFU}$ of $C$ rodentium (CR) by oral gavage (A). Shedding of $C$ rodentium was monitored in the feces at 3, 5, and 7 day post-infection (dpi) (B) and on necropsy, colon length was measured (C) and tissue processed for histopathology scoring (D); representative H\&E sections shown (original mag., $x 2$ ). Panel (E) shows colonic levels of Ly6G ${ }^{+}$and $\mathrm{IL} 17^{+}$cells as determined by flow cytometry. Lipocalin-2 levels in feces collected at 7 dpi are shown in Panel (F). Real-time qPCR analysis of colonic IL-22, IL17, IFN- $\gamma$, and Reg3g mRNA (G) (data are means \pm SEM; $n=4-5$ mice; one-way ANOVA followed by Tukey's test for parametric data and Dunn multiple comparison test for nonparametric data; ${ }^{*} p<0.05,{ }^{* \star} p<0.01,{ }^{\star \star *} \mathrm{p}<0.001,{ }^{\star \star \star \star} \mathrm{p} \leq 0.0001$; M, outer layers of muscle; L, gut lumen; ${ }^{*}$ inflammatory infiltrate). 


\section{A

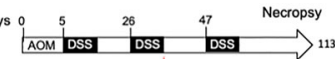 $1 \times 10^{\circ} M(L, 4)$ on day 33

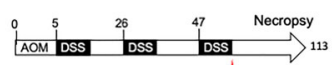 Ix10 M(L4) on day 54}

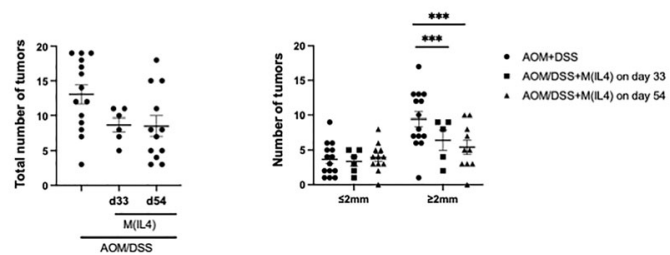

D

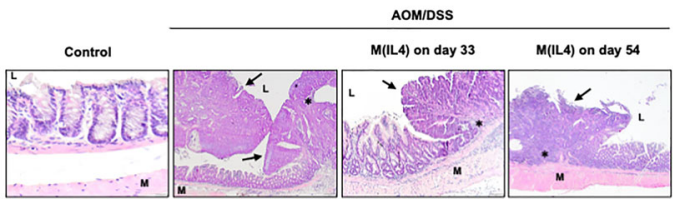

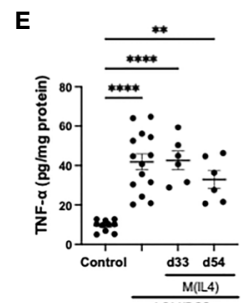
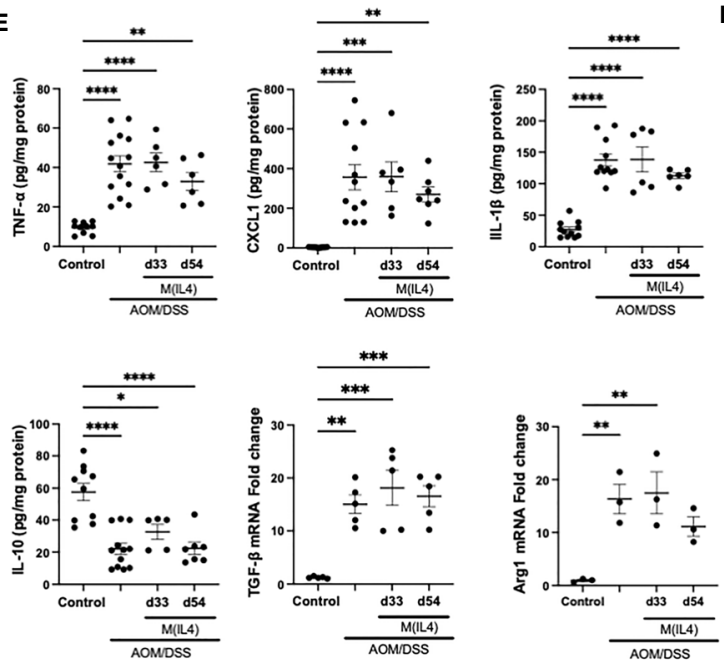

$\mathbf{F}$
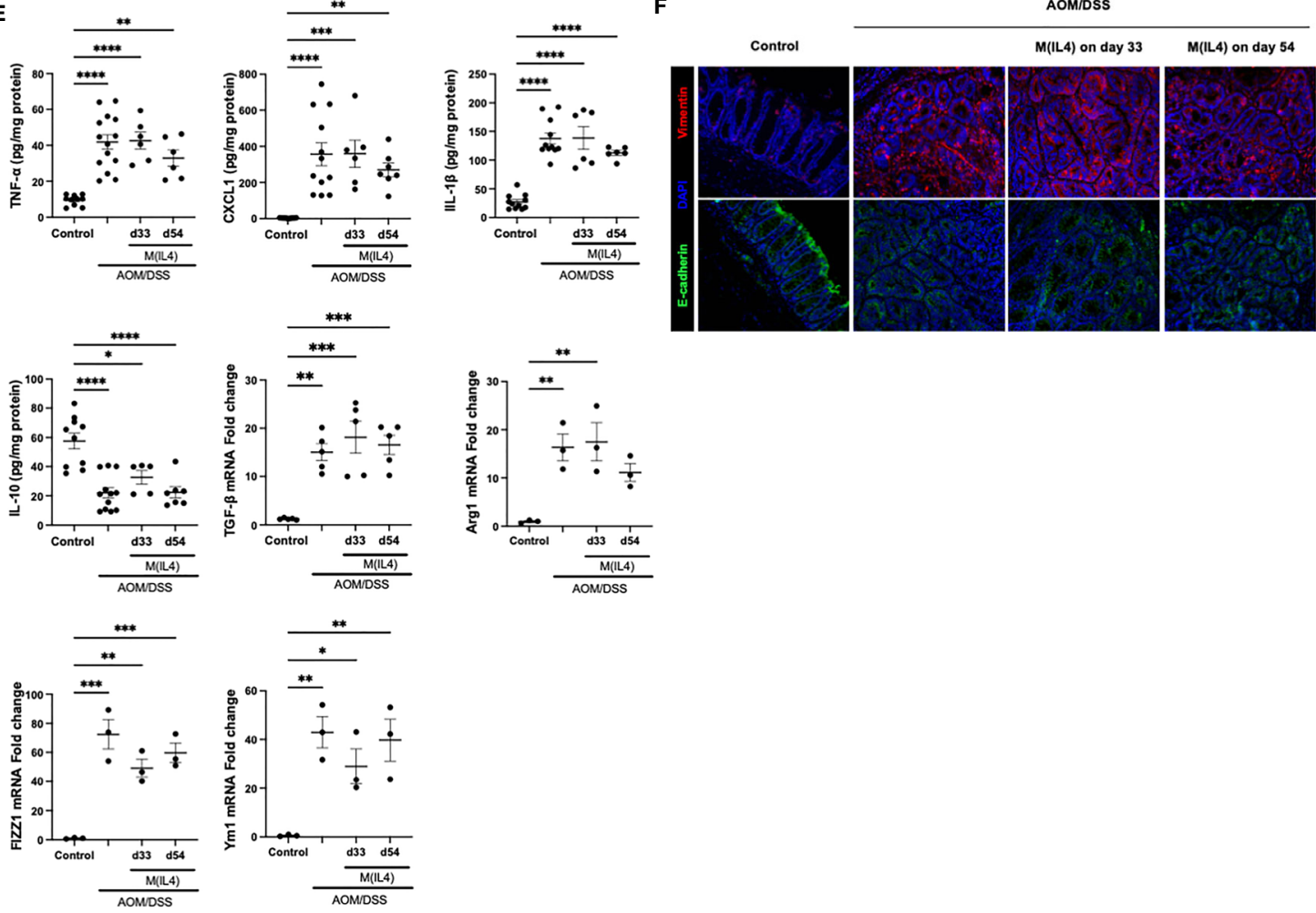

FIGURE 3 | M(IL4)s do not exaggerate colitis-associated colon cancer. Male C57BL/6J mice were treated as shown in panel (A) (azoxymethane (AOM) 12.5 mg/Kg ip. and 2\% (wt./vol.) dextran sodium sulphate (DSS) in drinking water for 7 days), with $\mathrm{M}(\mathrm{IL} 4) \mathrm{s}\left(1 \times 10^{6}\right.$, ip.) given in two paradigms. On necropsy at day 113 , colons were photographed and tumors counted and measured (B, C), and tissue processed for

histological assessment, with representative H\&E images shown in (D) (original mag., x20; M, muscle; L, lumen; arrow, neoplastic lesions; *, mixed lymphocyte, plasma cell, and neutrophil infiltrate). Panel (E) shows colonic levels of cytokines (mRNA for TGFB) and APCR data of arginase -1 (Arg1), FIZZ1 and Ym1 in colon extracts. Panel (F) shows representative images of mid-colonic tissue immunostained for vimentin or Ecadherin (DAPI as nuclear stain) (data are means \pm SEM; one-way ANOVA followed by Tukey's test, ${ }^{*} p<0.05,{ }^{* \star} p<0.01,{ }^{* \star *} p<0.001,{ }^{* \star * *} p \leq 0.0001$ ). 


\section{A}

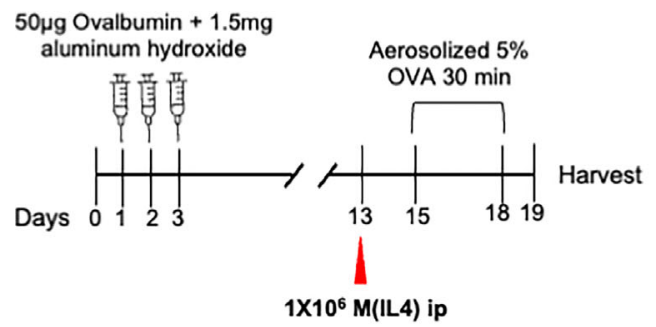

B
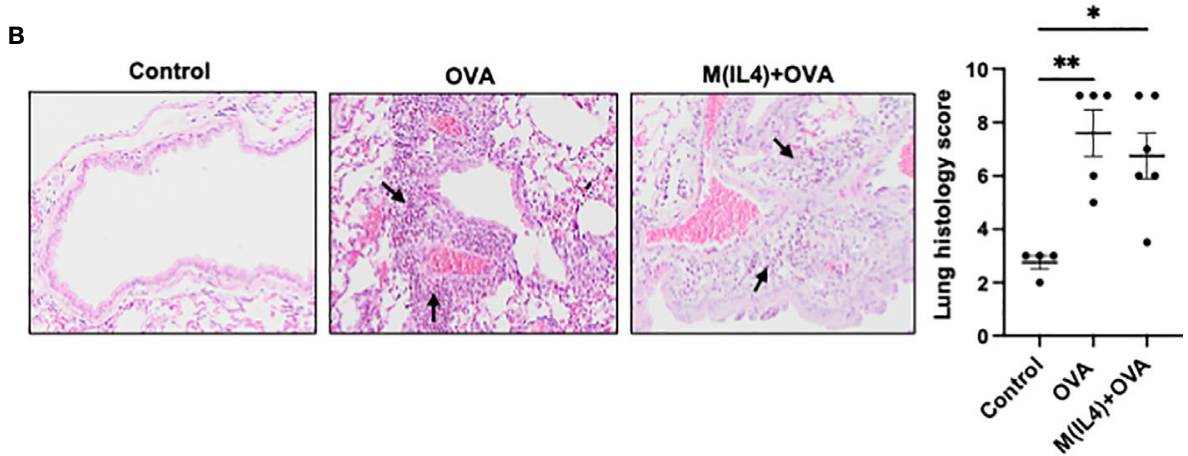

C

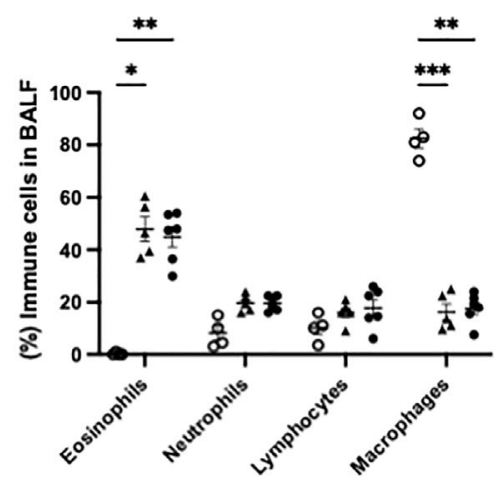

D
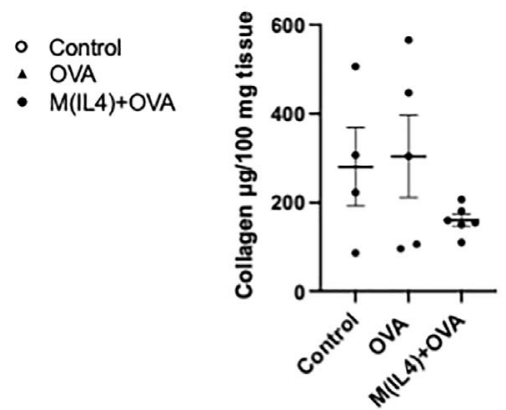

FIGURE 4 | M(IL4)s do not exacerbate airway inflammation in OVA-induced asthma. Male BALB/c mice were treated as shown in panel (A). Formalin-fixed lungs were assessed for histopathology using H\&E sections (arrows, eosinophils infiltration) (B). Percentage of immune cells was performed on H\&E-stained cytospin of bronchoalveolar lavage fluid (BALF) (C), and total lung collagen levels were measured by commercial colorimetric assay (D) (data are means \pm SEM; $n=5$; one-way analysis of variance followed by Tukey's test; $\left.{ }^{\star} p<0.05,{ }^{* \star} p<0.01,{ }^{* \star *} p<0.001\right)$.

with $\mathrm{M}(\mathrm{IL} 4 \mathrm{~s})$ then challenged with $C$. rodentium. Rather than rendering the mice vulnerable to $C$. rodentium, mice treated with M(IL4)s showed enhanced protection against infection and less colonic histopathology that correlated with reduced mRNA expression of IL-22, IL-17 and IFN $\gamma$, hallmarks of $C$. rodentium-colitis. These data appear to contradict Weng et al. who reported that AAMs mediated the exacerbation of $C$. rodentium infection in mice infected with the parasitic helminth, Heligmosomoides polygyrus (22). However, while evidence of accumulation of AAMs in the co-infected mice was presented (IL-4 increases following $H$. polygyrus-infection), numerous factors in this in vivo setting could have affected AAM activity. Indeed, the bactericidal capacity of AAMs is not clear, with increased and decreased phagocytosis and killing of bacteria being reported (41-43). We speculate that this reflects the plasticity of the macrophage and potentially the confusion created by considering AAMs as a single group. Nevertheless, having confirmed the anti-colitic effect of the M(IL4)s used here, the murine M(IL4) was found to reduce the severity of inflammation induced by $C$. rodentium, suggesting that susceptibility to bacterial infection need not be a significant side effect of M(IL4) therapy.

Chronic inflammation is a hallmark of cancer and patients who suffer from ulcerative colitis are at higher risk of developing CRC (38). Macrophage association with tumors is well documented, and whether described as TAMs, AAM or M2cells, the immunosuppressive nature of these cells via cognate ligands or the release of soluble signals has been linked to tumor progression by suppression of anti-tumor immunity (44). For example, the number of M2-macrophages, identified as $\mathrm{CD} 8^{+} \mathrm{CD} 163^{+}$cells on tissue sections, correlated with the progression and invasion of CRC (45). So while the link with 
immunosuppressive macrophages and CRC is not disputed, these cells are not identical to in vitro differentiated M(IL4)s; yet, the similarity between M(IL4)s and TAMs [e.g. both make TGF $\beta$ (46)], raises the possibility that M(IL4)s could promote CRC. Exploring this with the AOM/DSS model of CRC, we find that M(IL4)s delivered early or later in the development of CRC did not increase the progression or severity of disease. While there was a reduction in the number of tumors $>2 \mathrm{~mm}$ diameter in $\mathrm{M}(\mathrm{IL} 4)+\mathrm{AOM} / \mathrm{DSS}$ treated mice, the general pattern was that systemic delivery of M(IL4)s had negligible impact on the outcome of CRC in this model system. However, the reduction in the number of $>2 \mathrm{~mm}$ tumors is intriguing and may suggest less invasiveness (i.e. malignancy), or that transient suppression of inflammation following M(IL4) administration slowed polyp growth. Preliminary studies transferring $\mathrm{M}(0) \mathrm{s}$, revealed that this group of macrophages affected neither the progression of the CRC nor tumor size, implying specificity in the M(IL4) affect.

We have noted that a portion of ip.-delivered M(IL4)s migrate to the colon (14), but their longevity there is unknown. Examination of arginase-1, FIZZ1, and Ym1 mRNA revealed increased expression in tissues from AOM/DSS-treated mice, which also occurred, but not to a greater extent, in colon from the M(IL4) co-treated mice. The significance of these findings are not clear, and, as mentioned, arginase-1, FIZZ1 and Ym1 expression is not restricted to M(IL4)s. The data herein suggest that their expression alone does not blunt the development of CRC, indicating that the reduction in average tumor size seen in M(IL4)-treated mice is likely not dependent on arginase-1, FIZZ1 or Ym1. We speculate, if M(IL4)s suppress inflammation-associated CRC (i.e. fewer larger tumors) this may require the presence of the cells and could be accomplished with repeated M(IL4) administrations: a possibility worthy of testing in future analyses.

From the perspective of developing M(IL4) as a therapy, the lack of an effect of M(IL4) transfer in the AOM/DSS model is encouraging. In fact, in some types of cancer, pro-inflammatory mediators such as IL-22, TNF- $\alpha$, MIP-3 $\alpha$, CXCL2, CXCL3 and other CXCR2 ligands indirectly contribute to tumor growth through the proliferation of epithelial cells (e.g. STAT3, NF$\kappa B)(47-49)$. In the current study, the reduction of tumor size could be due to the regulation of proliferation through some inflammatory mediators not assessed/identified in the current study. Yet, we would be remiss if we failed to mention some caveats (1): AOM/DSS is only one model of CRC and other timepoints of delivery in the regime were not considered although one would hypothesis that early delivery of M(IL4)s could be beneficial because of their anti-colitic ability (2); it is possible that in other models or in humans that in vivo factors [e.g. $\operatorname{IgG}_{4}(50)$ ] could promote an oncogenic phenotype in the M(IL4)s; and (3), while functionally equivalent in some aspects, human and murine $\mathrm{M}$ (IL4)s are not identical and findings with murine cells do not dismiss the possibility that human M(IL4)s could promote CRC, metastasis or cancer in other organs.

The macrophages' ability to promote collagen deposition is cause for concern in airways inflammation (51). Macrophage accumulation in the lung is characteristic of murine models of allergic asthma (33) (Figure 4) and the cells often bear the hallmarks of AAM/M(IL4)s (e.g. arginase- $1^{+}, \mathrm{FIZZ1}^{+}, \mathrm{Ym}^{+}$). Treatment with agents that block AAM activity can reduce the severity of disease in models of airway hypersensitivity/asthma $(52,53)$, although such studies cannot rule out non-macrophage effects of the drugs. In contrast, others suggest that arginase $-1^{+}$ AAMs can be anti-fibrotic (54) and repeated treatments of M(IL4)s over a three-week period did not elicit increased collagen deposition in the lungs (liver, spleen or colon) of mice co-treated with DNBS (13). Intravenous delivery of helminthevoked AAMs reduced airways inflammation (55), while intranasal administration of an arginase $-1^{+} / \mathrm{FIZZ1}^{+}$AAM obtained from antibiotic-treated mice increased inflammation in the airway (56): this study also showed that intra-nasal M(IL4) delivery evoked lung eosinophilia, while intraperitoneal injection of AAMs reduced eosinophilia in allergic asthma (52). Intermediate between studies indicating that AAMs can promote airways inflammation (53) and others suggesting a benefit of AAMs in allergic conditions, the present study showed in vitro differentiated M(IL4)s given prior to allergen challenge had no effect in an OVA-model of airways hypersensitivity. M(IL4)-treated mice did not display an increase in collagen indicating no propensity towards fibrosis in this acute model setting. A variety of chemical and allergen models of airways inflammation are available, and it will be important to determine if M(IL4)s affect the inflammation, fibrosis or lung function in these models (57).

We speculate that the lack of consensus on the role of AAMs in airways inflammation indicates the spectrum of activity within this cell population, and that clarity may arise by adherence to descriptive nomenclature as presented by Murray and colleagues (58). It seems that the route of AAM or M(IL4) delivery affects the pro-inflammatory versus anti-inflammatory outcome in the airways, and in this context, it is noteworthy that intraperitoneal injected M(IL4)s did not accumulate in mouse lungs over a 5 day time-course (13). Also, the role of the microbiota in modifying the outcome of macrophage transfer should not be overlooked (44). Thus, it will be important to monitor lung function in any adoptive macrophage treatment strategy (59).

Having demonstrated the anti-colitic effect of M(IL4)s and the preservation of gut barrier function, the current study yielded no data to suggest that M(IL4) therapy would exaggerate or leave an individual more vulnerable to concomitant infection, CRC or airways inflammation. These observational data are presented in support of M(IL4) cellular therapy and could be augmented by mechanistic studies to elucidate, for example, how the administration of $\mathrm{M}$ (IL4)s resulted in reduced polyp size in the AOM/DSS model of CRC. We recognize that the range of potential side effects of any new therapy is large and we have considered but three of these, and that further testing of M(IL4)s in variations of the models presented herein and other disease model systems is important to garner a more holistic view of the M(IL4) in disease. Given that sex-differences have been noted in disease, it will be important to broaden the assessment of putative M(IL4) side effects by performing experiments with female mice (and also young and old animals) in models of 
disease. Thus, continued research efforts are required to precisely elucidate the anti-colitic mechanism of M(IL4)s and to test M(IL4)s in other models of infection, cancer and inflammatory disease (e.g. cirrhosis) (60), and to complement such studies it will be essential to assess putative side effects of human M(IL4)s in suitable model systems (20).

\section{DATA AVAILABILITY STATEMENT}

The raw data supporting the conclusions of this article will be made available by the authors, without undue reservation.

\section{ETHICS STATEMENT}

The animal study was reviewed and approved by University Calgary Animal Care Committee in compliance with the guidelines of the Canadian Council on Animal Care and administered under protocol AC17-0115.

\section{AUTHOR CONTRIBUTIONS}

$\mathrm{BC}$, project design, data collection and analysis, manuscript writing \& review. GB, data collection and analysis, manuscript review. NJ, data collection and analysis, manuscript review. AW, data collection and analysis, manuscript review. $\mathrm{AB}$, data

\section{REFERENCES}

1. Mosser DM, Edwards JP. Exploring the Full Spectrum of Macrophage Activation. Nat Rev Immunol (2008) 12:958-69. doi: 10.1038/nri2448

2. Bosurgi L, Cao YG, Cabeza-Cabrerizo M, Tucci A, Hughes LD, Kong Y, et al. Macrophage Function in Tissue Repair and Remodeling Requires IL-4 or IL-13 With Apoptotic Cells. Sci (2017) 6342:1072-6. doi: 10.1126/science.aai8132

3. Kim SY, Nair MG. Macrophages in Wound Healing: Activation and Plasticity. Immunol Cell Biol (2019) 3:258-67. doi: 10.1111/imcb.12236

4. Zhang QZ, Su WR, Shi SH, Wilder-Smith P, Xiang AP, Wong A, et al. Human Gingiva-Derived Mesenchymal Stem Cells Elicit Polarization of M2 Macrophages and Enhance Cutaneous Wound Healing. Stem Cells (2010) 10:1856-68. doi: 10.1002/stem.503

5. Melief SM, Schrama E, Brugman MH, Tiemessen MM, Hoogduijn MJ, Fibbe WE, et al. Multipotent Stromal Cells Induce Human Regulatory T Cells Through a Novel Pathway Involving Skewing of Monocytes Toward AntiInflammatory Macrophages. Stem Cells (2013) 9:1980-91. doi: 10.1002/ stem. 1432

6. Savage ND, de Boer T, Walburg KV, Joosten SA, van Meijgaarden K, Geluk A, et al. Human Anti-Inflammatory Macrophages Induce Foxp3+ GITR+ CD25 + Regulatory T Cells, Which Suppress via Membrane-Bound TGFbeta-1. J Immunol (2008) 3:2220-6. doi: 10.4049/jimmunol.181.3.2220

7. Podaru MN, Fields L, Kainuma S, Ichihara Y, Hussain M, Ito T, et al. Reparative Macrophage Transplantation for Myocardial Repair: A Refinement of Bone Marrow Mononuclear Cell-Based Therapy. Basic Res Cardiol (2019) 5:34. doi: 10.1007/s00395-019-0742-1

8. Parsa R, Andresen P, Gillett A, Mia S, Zhang XM, Mayans S, et al. Adoptive Transfer of Immunomodulatory M2 Macrophages Prevents Type 1 Diabetes in NOD Mice. Diabetes (2012) 11:2881-92. doi: 10.2337/db11-1635

9. Zhang XM, Lund H, Mia S, Parsa R, Harris RA. Adoptive Transfer of Cytokine-Induced Immunomodulatory Adult Microglia Attenuates collection and analysis, manuscript review. KK, blinded tissue scoring, analysis and manuscript review. RW, manuscript review. MK, blinded tissue scoring, analysis and manuscript review. EC, manuscript review. DM, project design, grant support, analysis, manuscript writing and review. All authors contributed to the article and approved the submitted version.

\section{FUNDING}

This work was supported by a Grant-in-Aid from Crohn's Colitis Canada to DM. BC is supported by an Alberta Innovates-Health Sciences Post-doctoral Fellowship. NJ is supported by the Francis Family Foundation as a Parker B Francis Fellow. Work from the Cobo laboratory is supported by a Discovery Grant from the Natural Sciences and Engineering Council of Canada (NSERC), RGPAS-2017-507827.

\section{ACKNOWLEDGMENTS}

We thank Yi Lin Tan for assistance with the C. rodentium model.

\section{SUPPLEMENTARY MATERIAL}

The Supplementary Material for this article can be found online at: https://www.frontiersin.org/articles/10.3389/fimmu.2021. 744738/full\#supplementary-material

Experimental Autoimmune Encephalomyelitis in DBA/1 Mice. Glia (2014) 5:804-17. doi: 10.1002/glia.22643

10. Du Q, Tsuboi N, Shi Y, Ito S, Sugiyama Y, Furuhashi K, et al. Transfusion of CD206+ M2 Macrophages Ameliorates Antibody-Mediated Glomerulonephritis in Mice. Am J Pathol (2016) 12:3176-88. doi: 10.1016/ j.ajpath.2016.08.012

11. Ma SF, Chen YJ, Zhang JX, Shen L, Wang R, Zhou JS, et al. Adoptive Transfer of M2 Macrophages Promotes Locomotor Recovery in Adult Rats After Spinal Cord Injury. Brain Behav Immun (2015) 45:157-70. doi: 10.1016/ j.bbi.2014.11.007

12. Hunter MM, Wang A, Parhar KS, Johnston MJ, Van Rooijen N, Beck PL, et al. In Vitro-Derived Alternatively Activated Macrophages Reduce Colonic Inflammation in Mice. Gastroenterol (2010) 138:1395-405. doi: 10.1053/ j.gastro.2009.12.041

13. Leung G, Wang A, Fernando M, Phan VC, McKay DM. Bone MarrowDerived Alternatively Activated Macrophages Reduce Colitis Without Promoting Fibrosis: Participation of IL-10. Am J Physiol Gastrointestinal liver Physiol (2013) 304:G781-92. doi: 10.1152/ajpgi.00055.2013

14. Leung G, Petri B, Reyes JL, Wang A, Iannuzzi J, McKay DM. Cryopreserved IL-4-Treated Macrophages Attenuate Murine Colitis in an Integrin Beta7Dependent Manner. Mol Med (2015) 21:924-6. doi: 10.2119/ molmed.2015.00193

15. Weisser SB, Kozicky LK, Brugger HK, Ngoh EN, Cheung B, Jen R, et al. Arginase Activity in Alternatively Activated Macrophages Protects PI3Kp110delta Deficient Mice From Dextran Sodium Sulfate Induced Intestinal Inflammation. Eur J Immunol (2014) 44:3353-67. doi: 10.1002/ eji.201343981

16. Rizzo A, Monteleone I, Fina D, Stolfi C, Caruso R, Fantini MC, et al. Inhibition of Colitis by IL-25 Associates With Induction of Alternatively Activated Macrophages. Inflammatory bowel dis (2012) 18:449-59. doi: 10.1002/ibd.21799 
17. Enderlin Vaz da Silva Z, Lehr HA, Velin D. In Vitro and In Vivo Repair Activities of Undifferentiated and Classically and Alternatively Activated Macrophages. Pathobiol (2014) 81:86-93. doi: 10.1159/000357306

18. Haribhai D, Ziegelbauer J, Jia S, Upchurch K, Yan K, Schmitt EG, et al. Alternatively Activated Macrophages Boost Induced Regulatory T and Th17 Cell Responses During Immunotherapy for Colitis. J Immunol (2016) 196:3305-17. doi: 10.4049/jimmunol.1501956

19. Jin X, Bai X, Zhao Y, Dong Z, Pang J, Liu M, et al. Nrf2 Participates in M2 Polarization by Trichinella Spiralis to Alleviate TNBS-Induced Colitis in Mice. Front Immunol (2021) 12:698494. doi: 10.3389/fimmu.2021.698494

20. Jayme TS, Leung G, Wang A, Workentine ML, Rajeev S, Shute A, et al. Human Interleukin-4-Treated Regulatory Macrophages Promote Epithelial Wound Healing and Reduce Colitis in a Mouse Model. Sci Adv (2020) 23:eaba4376. doi: 10.1126/sciadv.aba4376

21. Kamper P, Bendix K, Hamilton-Dutoit S, Honoré B, Nyengaard JR, d'Amore F. Tumor-Infiltrating Macrophages Correlate With Adverse Prognosis and Epstein-Barr Virus Status in Classical Hodgkin's Lymphoma. Haematol (2011) 96:269-76. doi: 10.1038/s41598-020-66010-z

22. Weng M, Huntley D, Huang IF, Foye-Jackson O, Wang L, Sarkissian A, et al. Alternatively Activated Macrophages in Intestinal Helminth Infection: Effects on Concurrent Bacterial Colitis. J Immunol (2007) 179:4721-31. doi: 10.4049/ jimmunol.179.7.4721

23. Callejas BE, Mendoza-Rodríguez MG, Villamar-Cruz O, Reyes-Martínez S, Sánchez-Barrera CA, Rodríguez-Sosa M, et al. Helminth-Derived Molecules Inhibit Colitis-Associated Colon Cancer Development Through NF-kb and STAT3 Regulation. Int J Cancer (2019) 145:3126-39. doi: 10.1002/ijc.32626

24. Wang A, Keita $\AA$, Phan V, McKay CM, Schoultz I, Lee J, et al. Targeting Mitochondria-Derived Reactive Oxygen Species to Reduce Epithelial Barrier Dysfunction and Colitis. Am J Pathol (2014) 184:2516-27. doi: 10.1016/ j.ajpath.2014.05.019

25. Hunter MM, Wang A, Hirota CL, McKay DM. Neutralizing Anti-IL-10 Antibody Blocks the Protective Effect of Tapeworm Infection in a Murine Model of Chemically Induced Colitis. J Immunol (2005) 174:7368-75. doi: 10.4049/jimmunol.174.11.7368

26. Holani R, Babbar A, Blyth GAD, Lopes F, Jijon H, McKay DM, et al. Cathelicidin-Mediated Lipopolysaccharide Signaling via Intracellular TLR4 in Colonic Epithelial Cells Evokes CXCL8 Production. Gut Microbes (2020) 12:1785802. doi: 10.1080/19490976.2020.1785802

27. Koroleva EP, Halperin S, Gubernatorova EO, Macho-Fernandez E, Spencer CM, Tumanov AV. Citrobacter Rodentium-Induced Colitis: A Robust Model to Study Mucosal Immune Responses in the Gut. J Immunol Methods (2015) 421:61-72. doi: 10.1016/j.jim.2015.02.003

28. Tanaka T. Development of an Inflammation-Associated Colorectal Cancer Model and Its Application for Research on Carcinogenesis and Chemoprevention. Int $J$ Inflam (2012) 2012:658786. doi: 10.1155/2012/658786

29. Jendzjowsky NG, Roy A, Barioni NO, Kelly MM, Green FHY, Wyatt CN, et al. Preventing Acute Asthmatic Symptoms by Targeting a Neuronal Mechanism Involving Carotid Body Lysophosphatidic Acid Receptors. Nat Commun (2018) 9:4030. doi: 10.1038/s41467-018-06189-y

30. Schuster M, Tschernig T, Krug N, Pabst R. Lymphocytes Migrate From the Blood Into the Bronchoalveolar Lavage and Lung Parenchyma in the Asthma Model of the Brown Norway Rat. Am J Respir Crit Care Med (2000) 161:55866. doi: 10.1164/ajrccm.161.2.9812021

31. Zeldin DC, Wohlford-Lenane C, Chulada P, Bradbury JA, Scarborough PE, Roggli V, et al. Airway Inflammation and Responsiveness in Prostaglandin $\mathrm{H}$ Synthase-Deficient Mice Exposed to Bacterial Lipopolysaccharide. Am J Respir Cell Mol Biol (2001) 25:457-65. doi: 10.1165/ajrcmb.25.4.4505

32. Lee C, Jeong H, Bae Y, Shin K, Kang S, Kim H, et al. Targeting of M2-Like Tumor-Associated Macrophages With a Melittin-Based Pro-Apoptotic Peptide. J Immunother Cancer (2019) 7:147. doi: 10.1186/s40425-0190610-4

33. Girodet PO, Nguyen D, Mancini JD, Hundal M, Zhou X, Israel E, et al. Alternative Macrophage Activation Is Increased in Asthma. Am J Respir Cell Mol Biol (2016) 55:467-75. doi: 10.1165/rcmb.2015-0295OC

34. Cao Y, Ding Z, Han C, Shi H, Cui L, Lin R. Efficacy of Mesenchymal Stromal Cells for Fistula Treatment of Crohn's Disease: A Systematic Review and Meta-Analysis. Dig Dis Sci (2017) 62:851-60. doi: 10.1007/s10620-017-4453-x
35. Canavan JB, Scotta C, Vossenkamper A, Goldberg R, Elder MJ, Shoval I, et al. Developing In Vitro Expanded CD45RA+ Regulatory T Cells as an Adoptive Cell Therapy for Crohn's Disease. Gut (2016) 65:584-94. doi: 10.1136/gutjnl2014-306919

36. Blériot C, Chakarov S, Ginhoux F. Determinants of Resident Tissue Macrophage Identity and Function. Immun (2020) 52:957-70. doi: 10.1016/ j.immuni.2020.05.014

37. Taveras NT, Martinex AR, KUmar R, Jamil A, Kumar B. Pulmonary Manifestations of Inflammatory Bowel Disease. Cureus (2021) 13:e14216. doi: 10.3748/wjg.v20.i37.13501

38. Wijnands A M, de Jong ME, Lutgens MWMD, Hoentjen F, Elias SG, Oldenburg B. Dutch Initiative on Crohn and Colitis (ICC). Prognostic Factors for Advanced Colorectal Neoplasia in Inflammatory Bowel Disease: Systematic Review and Meta-Analysis. Gastroenterol (2021) 160:1584-98. doi: 10.1053 /j.gastro.2020.12.036

39. Chassaing B, Koren O, Carvalho FA, Ley RE, Gewirtz AT. AIEC Pathobiont Instigates Chronic Colitis in Susceptible Hosts by Altering Microbiota Composition. Gut (2014) 63:1069-80. doi: 10.1136/gutjnl-2013-304909

40. Du Y, Rong L, Cong Y, Shen L, Zhang N, Wang B. Macrophage Polarization: An Effective Approach to Targeted Therapy of Inflamamtory Bowel Disease. Expert Opin Ther Targets (2021) 17:1-19. doi: 10.1080/14728222. 2021.1901079

41. Varin A, Mukhopadhyay S, Herbein G, Gordon S. Alternative Activation of Macrophages by IL-4 Impairs Phagocytosis of Pathogens But Potentiates Microbial-Induced Signalling and Cytokine Secretion. Blood (2010) 115:35362. doi: 10.1182/blood-2009-08-236711

42. Gratchev A, Kzhyshkowska J, Utikal J, Goerdt S. Interleukin-4 and Dexamethasone Counterregulate Extracellular Matrix Remodelling and Phagocytosis in Type-2 Macrophages. Scand J Immunol (2005) 61:10-7. doi: 10.1111/j.0300-9475.2005.01524.x

43. Kumaran Satyanarayanan S, El Kebir D, Soboh S, Butenko S, Sekheri M, Saadi J, et al. IFN- $\beta$ Is a Macrophage-Derived Effector Cytokine Facilitating the Resolution of Bacterial Inflammation. Nat Commun (2019) 10:3471. doi: 10.1038/s41467-019-10903-9

44. Mola S, Pandolfo C, Sica A, Porta C. The Macrophage-Microbiota Interplay in Colorectal Cancer (CRC)-Regulated Inflammation: Prognostic and Therapeutic Significance. Int J Mol Sci (2020) 21:6866. doi: 10.3390/ ijms 21186866

45. Inagaki K, Kunisho S, Takigawa H, Yuge R, Oka S, Tanaka S, et al. Role of Tumor-Associated Macrophages at the Invasive Front in Human Colorectal Cancer Progression. Cancer Sci (2021) 112:2692-704. doi: 10.1111/cas.14940

46. Wang HW, Joyce JA. Alternative Activation of Tumor-Associated Macrophages by IL-4: Priming for Protumoral Functions. Cell Cycle (2010) 24:4824-35. doi: 10.4161/cc.9.24.14322

47. Coussens LM, Werb Z. Inflammation and Cancer. Nat (2002) 6917:860-7. doi: 10.1038 /nature 01322

48. Chow MT, Luster AD. Chemokines in Cancer. Cancer Immunol Res (2014) 12:1125-31. doi: 10.1158/2326-6066.CIR-14-0160

49. Huang YH, Cao YF, Jiang ZY, Zhang S, Gao F. Th22 Cell Accumulation Is Associated With Colorectal Cancer Development. World J Gastroenterol (2015) 21:4216-24. doi: 10.3748/wjg.v21.i14.4216

50. Jordakieva G, Bianchini R, Reichhold D, Piehslinger J, Groschopf A, Jense SA, et al. IgG4 Induces Tolergenic M2-Like Macrophages and Correlates With Disease Progression in Colon Cancer. Oncoimmunol (2021) 10:1880687. doi: 10.1080/2162402X.2021.1880687

51. Hendersen NC, Rieder F, Wynn TA. Fibrosis: From Mechanisms to Medicines. Nat (2020) 587:555-66. doi: 10.1038/s41586-020-2938-9

52. Ford AQ, Dasgupta P, Mikhailenko I, Smith EM, Noben-Trauth N, Keegan AD. Adoptive Transfer of IL-4ro+ Macrophages Is Sufficient to Enhance Eosinophilic Inflammation in a Mouse Model of Allergic Lung Inflammation. BMC Immunol (2012) 13:6. doi: 10.1186/1471-2172-13-6

53. Moreira AP, Cavassani KA, Hullinger R, Rosada RS, Fong DJ, Murray L, et al. Serum Amyloid P Attenuates M2 Macrophage Activation and Protects Against Fungal Spore-Induced Allergic Airway Disease. J Allergy Clin Immunol (2010) 126:712-21.e7. doi: 10.1016/j.jaci.2010.06.010

54. Pesce JT, Ramalingam TR, Mentink-Kane MM, Wilson MS, El Kasmi KC, Smith AM, et al. Arginase-1-Expressing Macrophages Suppress Th2 
Cytokine-Driven Inflammation and Fibrosis. PloS Pathog (2009) 4:e1000371. doi: 10.1371/journal.ppat.1000371

55. Kang SA, Park MK, Park SK, Choi JH, Lee DI, Song SM, et al. Adoptive Transfer of Trichinella Spiralis-Activated Macrophages Can Ameliorate Both Th1- and Th2-Activated Inflammation in Murine Models. Sci Rep (2019) 9:6547. doi: 10.1038/s41598-019-43057-1

56. Kim Y-G, Udayanga KGS, Totsuka N, Weinberg JB, Núñez G, Shibuya A. Gut Dysbiosis Promotes M2 Macrophage Polarization and Allergic Airway Inflammation via Fungi-Induced PGE 2 . Cell Host Microbe (2014) 15:95102. doi: 10.1016/j.chom.2013.12.010

57. McMillan SJ, Lloyd CM. Prolonged Allergen Challenge in Mice Leads to Persistent Airway Remodelling. Clin Exp Allergy (2004) 34:497-507. doi: 10.1111/j.1365-2222.2004.01895.x

58. Murray PJ, Allen JE, Biswas SK, Fisher EA, Gilroy DW, Goerdt S, et al. Macrophage Activation and Polarization: Nomenclature and Experimental Guidelines. Immun (2014) 41:14-20. doi: 10.1016/j.immuni.2014.06.008

59. Moroni F, Dwyer BJ, Graham C, Pass C, Bailey L, Ritchie L, et al. Safety Profile of Autologous Macrophage Therapy for Liver Cirrhosis. Nat Med (2019) 25:1560-5. doi: 10.1038/s41591-019-0599-8

60. Starkey-Lewis P, Campana L, Aleksieva N, Cartwright JA, Mackinnon A, O'Duibhir E, et al. Alternatively Activated Macrophages Promote Resolution of Necrosis Following Acute Liver Injury. J Hepatol (2020) 73:349-60. doi: 10.1016/j.jhep.2020.02.031

Conflict of Interest: The authors declare that the research was conducted in the absence of any commercial or financial relationships that could be construed as a potential conflict of interest.

Publisher's Note: All claims expressed in this article are solely those of the authors and do not necessarily represent those of their affiliated organizations, or those of the publisher, the editors and the reviewers. Any product that may be evaluated in this article, or claim that may be made by its manufacturer, is not guaranteed or endorsed by the publisher.

Copyright $\odot 2021$ Callejas, Blyth, Jendzjowsky, Wang, Babbar, Koro, Wilson, Kelly, Cobo and McKay. This is an open-access article distributed under the terms of the Creative Commons Attribution License (CC BY). The use, distribution or reproduction in other forums is permitted, provided the original author(s) and the copyright owner(s) are credited and that the original publication in this journal is cited, in accordance with accepted academic practice. No use, distribution or reproduction is permitted which does not comply with these terms. 